\title{
What we need to know when performing and interpreting US elastography
}

\author{
So Hyun Park ${ }^{1,2}$, So Yeon Kim', Chong Hyun Suh", , Seung Soo Lee', Kyoung Won Kim', So Jung Lee', and Moon-Gyu Lee \\ 'Department of Radiology and Research Institute of Radiology, Asan Medical Center, University of Ulsan College of Medicine, Seoul; \\ 2Department of Radiology, Gil Medical Center, Gachon University, Incheon; ${ }^{3}$ Department of Radiology, Namwon Medical Center, \\ Namwon, Korea
}

According to the increasing need for accurate staging of hepatic fibrosis, the ultrasound (US) elastography techniques have evolved significantly over the past two decades. Currently, US elastography is increasingly used in clinical practice. Previously published studies have demonstrated the excellent diagnostic performance of US elastography for the detection and staging of liver fibrosis. Although US elastography may seem easy to perform and interpret, there are many technical and clinical factors which can affect the results of US elastography. Therefore, clinicians who are involved with US elastography should be aware of these factors. The purpose of this article is to present a brief overview of US techniques with the relevant technology, the clinical indications, diagnostic performance, and technical and biological factors which should be considered in order to avoid misinterpretation of US elastography results.

(Clin Mol Hepatol 2016;22:406-414)

Keywords: Ultrasound elastography; Transient elastography; Shear wave elastography; Liver fibrosis, Liver stiffness

\section{INTRODUCTION}

Hepatic fibrosis correlates with the severity of chronic liver damage. In the era of antiviral and antifibrotic therapy, noninvasive detection and quantification of hepatic fibrosis is becoming more and more important.' Although liver biopsy is the current gold standard for assessing hepatic fibrosis, the problems of liver biopsy are its high rates of sampling errors, invasiveness, difficulty to repeat, and observer variability. Therefore, liver biopsy is not an ideal tool for screening, longitudinal monitoring, and assessing the therapeutic response. The ideal test for the staging of hepatic fibrosis should be noninvasive, simple, readily available, not ex- pensive, reproducible, and accurate. Given these conditions, US elastography have many advantages in becoming the ideal test for quantifying hepatic fibrosis.

US elastography techniques have evolved significantly over the past two decades. US elastography is not only an active area of research, but has also been implemented in clinical practice. According to its rapid development and adaptation from engineering and many vendors, variable terminology and parameters have been used, which can be very confusing. Recently, the European Federation of Societies for Ultrasound in Medicine and Biology (EFSUMB), ${ }^{2,3}$ the World Federation for Ultrasound in Medicine and Biology and Biology (WFUMB), ${ }^{4,5}$ and the Society of Radiologists

\section{Abbreviations:}

$A L T$, alanine aminotransferase; ARFI, acoustic radiation force impulse; EFSUMB, European Federation of Societies for Ultrasound in Medicine and Biology; HBV, hepatitis B virus; HCV, hepatitis C virus; HVPG, hepatic venous pressure gradient; ICC, intraclass correlation coefficient; IQR, interquartile range; LSM, liver stiffness measurement; NAFLD, nonalcoholic fatty liver disease; PSWSM, point shear wave speed measurement; QIBA, Quantitative Imaging Biomarkers Alliance; STARD, Standards for Reporting of Diagnostic Accuracy Studies; SWS, Shear Wave Speed; TE, transient elastography; US, ultrasound; WFUMB, World Federation for Ultrasound in Medicine and Biology and Biology

\section{Corresponding author : So Yeon Kim}

Department of Radiology and Research Institute of Radiology, Asan Medical Center, University of Ulsan College of Medicine, 88 Olympic-Ro 43-gil, Songpa-gu, Seoul 05505, Korea

Tel: +82-2-3010-5980, Fax: +82-2-476-4719

E-mail:sykimrad@amc.seoul.kr 
Table 1. Recommended Terminology for Describing the Methods for and Parameters of US Elastography

\begin{tabular}{|c|c|}
\hline Term & Definition \\
\hline $\begin{array}{l}\text { Acoustic radiation force } \\
\text { impulse (ARFI) }\end{array}$ & A temporally impulse-like acoustic radiation force used to generate a focused acoustic beam. \\
\hline $\begin{array}{l}\text { Point shear wave } \\
\text { elastography }\end{array}$ & $\begin{array}{l}\text { A type of elastography. By generating a shear wave using an acoustic radiation force, it provides the expected } \\
\text { value of a quantitative stiffness metric (shear wave speed) for the assumed homogenous local region of } \\
\text { interest. }\end{array}$ \\
\hline Shear wave & A type of transverse elastic wave whose motion is perpendicular to the direction of the particle. \\
\hline Shear wave elastography & $\begin{array}{l}\text { A type of elastography which generates shear waves using an acoustic radiation force and induces images of a } \\
\text { stiffness metric and depicted by the color bar that represents either Young's modulus or the shear wave speed. }\end{array}$ \\
\hline Stiffness & The extent to which an object resists deformation in response to an applied force. \\
\hline Transient elastography & $\begin{array}{l}\text { A non-invasive elasticity estimation method of generating a shear wave using an external vibration. It provides } \\
\text { a quantitative stiffness metric (Young's modulus) which provides its expected value for the homogenous local } \\
\text { region. }\end{array}$ \\
\hline
\end{tabular}

Table 2. Classification of US elastography of the liver

\begin{tabular}{|c|c|c|c|c|}
\hline Techniques & $\begin{array}{l}\text { Measured physical } \\
\text { quality }\end{array}$ & $\begin{array}{l}\text { Excitation } \\
\text { methods }\end{array}$ & Modalities & Commercial products (Manufacturer) \\
\hline \multirow[t]{3}{*}{ Shear wave imaging } & Shear wave speed & $\begin{array}{l}\text { Mechanical external } \\
\text { vibration }\end{array}$ & Transient elastography & Fibroscan (Echogen) \\
\hline & & $\begin{array}{l}\text { Acoustic radiation } \\
\text { force impulse } \\
\text { excitations }\end{array}$ & $\begin{array}{l}\text { Point shear wave speed } \\
\text { measurement }\end{array}$ & $\begin{array}{l}\text { Virtual Touch Quantification (Siemens } \\
\text { Healthcare); ElastPQ (Philips); Smart-Shearwave } \\
\text { elastography (Samsung Medison) }\end{array}$ \\
\hline & & & $\begin{array}{l}\text { Shear wave speed } \\
\text { imaging }\end{array}$ & $\begin{array}{l}\text { ShearWave Elastography (Aixplorer SuperSonic } \\
\text { Imagine); Virtual Touch Image Quantification, } \\
\text { (Siemens Healthcare); Shear Wave } \\
\text { elastography (GE Healthcare); Shear Wave } \\
\text { Elastography (Toshiba Medical Systems) }\end{array}$ \\
\hline Strain imaging & $\begin{array}{l}\text { Strain or } \\
\text { displacement }\end{array}$ & $\begin{array}{l}\text { Manual compression } \\
\text { or acoustic radiation } \\
\text { force impulse }\end{array}$ & & $\begin{array}{l}\text { Real-time tissue elastography (Hitachi); Virtual } \\
\text { Touch Imaging (Siemens Healthcare) }\end{array}$ \\
\hline
\end{tabular}

in Ultrasound ${ }^{6}$ have proposed guidelines and recommendations for US elastography. Beginning in 2012, the Quantitative Imaging Biomarkers Alliance (QIBA) of the Radiological Society of North America also organized the Ultrasound Shear Wave Speed (SWS) Biomarker Committee (http://qibawiki.rsna.org/index.php/Ultrasound_SWS_Biomarker_Ctte) as part of its continuing efforts to improve the value and practicality of the quantitative values obtained from US elastography. European experts also suggested an extension of the Standards for Reporting of Diagnostic Accuracy Studies (STARD) for reporting diagnostic accuracy studies on liver fibrosis tests, i.e. the Liver FibroSTARD standards.' In this review, the terms defined by the WFUMB are mainly used in order to facilitate the uniformity of the description (Table 1).

Although US elastography may seem easy to perform and interpret, it's not a magic calculator. As there are many technical and clinical factors which can affect the results of US elastography, the interpretation of US results without appropriate knowledge might lead to misinterpretation. The purpose of this article is to present a brief overview of US techniques with their relevant technology, clinical indications, diagnostic performance, and technical and biological factors which should be considered in order to avoid misinterpretation.

\section{OVERVIEW OF US ELASTOGRAPHY TECHNIQUES}

US elastography techniques can be categorized into the stain imaging and the shear wave imaging according to the physical quantity each technique measures (Table 2). As strain imaging generally does not provide the absolute values of liver stiffness, it will not be further discussed in this review. 

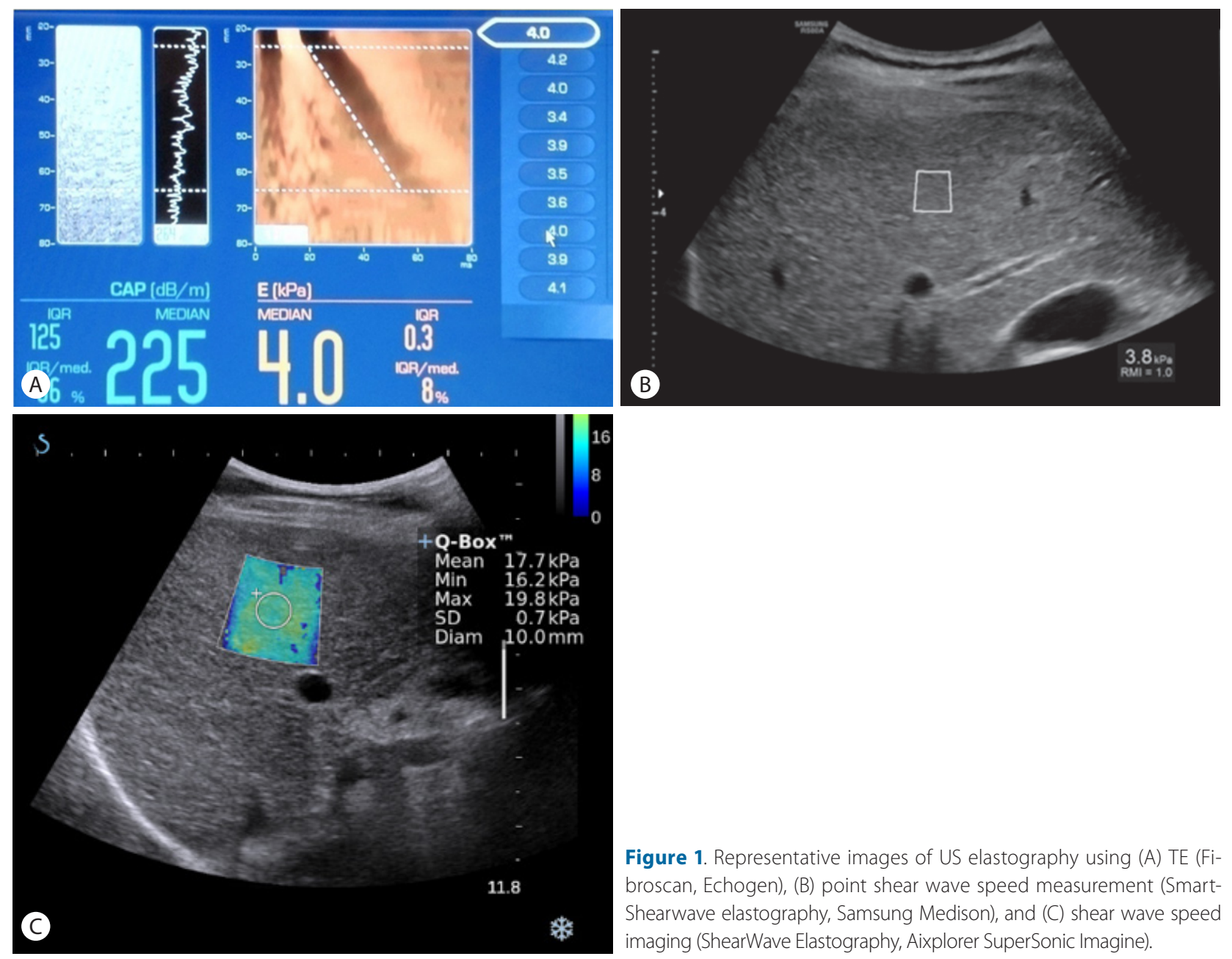

Figure 1. Representative images of US elastography using (A) TE (Fibroscan, Echogen), (B) point shear wave speed measurement (SmartShearwave elastography, Samsung Medison), and (C) shear wave speed imaging (ShearWave Elastography, Aixplorer SuperSonic Imagine).

For the shear wave imaging, the physical quantity which is measured is the velocity of shear waves, and/or Young's modulus ( $\mathrm{kPa}$ ) is converted from shear wave speed based on assumptions of constant density, homogeneity, isotropy, and static deformation using the equation for Young's elastic modulus $\left(E=3 \rho v^{2}\right.$, where $\rho$ is the shear wave velocity $(\mathrm{m} / \mathrm{sec})$ and $\rho$ is the density of tissue, assumed to be constant). ${ }^{8,9}$ As we can see in this formula, the velocity of the shear wave increases with the stiffness of the liver parenchyma.

There are three methods for the shear wave imaging, i.e. transient elastography (TE); point shear wave speed measurement; and shear wave speed imaging. In order to generate shear waves, shear wave imaging can use a controlled, vibrating, external vibration in TE (Fibroscan, Echogen) or an acoustic radiation force impulse (ARFI) in point shear wave speed measurement (Virtual Touch Quantification, Siemens Healthcare; ElastPQ, Philips; Smart-Shearwave elastography, Samsung medison, Seoul, Korea) and shear wave speed imaging (ShearWave Elastography, Aixplorer Super-
Sonic Imagine; Virtual Touch Image Quantification, Siemens Healthcare; Shear Wave elastography, GE Healthcare; Shear Wave Elastography, Toshiba Medical Systems, Tochigi Otawara, Japan) (Table 2) (Fig. 1). While TE is not integrated into gray scale US, the method using ARFI excitation is integrated with gray scale US with conventional US probes (Fig. 1). The point shear wave speed measurement provides liver stiffness values of only a region of interest, while shear wave speed imaging shows real time imaging with a simultaneous display of gray scale US and a color elastogram map in which a quantitative measurement is possible (Fig. 1).

\section{CLINICAL INDICATIONS FOR US ELASTOGRAPHY}

\section{Noninvasive assessment of liver fibrosis}

The main clinical indication for US elastography is the noninva- 
sive assessment of liver fibrosis in patients with chronic liver disease. The histologic fibrosis grade is well correlated with the liver stiffness values measured on US elastography. ${ }^{10,11}$ The diagnostic performance of US elastography will be discussed in the following text.

\section{Longitudinal monitoring of the treatment response and disease progression}

Owing to its noninvasiveness, liver stiffness measured by US elastography is useful for assessing the longitudinal monitoring of the treatment response and disease progression. ${ }^{12-16}$ In a study of 416 chronic hepatitis C patients, the sustained virological response with antiviral therapy was associated with a significant decline of liver stiffness seen on TE. ${ }^{13}$

\section{Portal hypertension and prediction of complications of cirrhosis}

The standard method for evaluating portal hypertension is the measurement of the hepatic venous pressure gradient (HVPG) which, however, is an invasive technique requiring hepatic venous catheterization. US elastography can be a noninvasive alternative used to estimate the severity of portal hypertension and to predict complications associated with liver cirrhosis. In previously published studies, liver stiffness measurement by TE was positively correlated with HVPG ${ }^{17,18}$. The AUROC for the prediction of HVPG $\geq 10 \mathrm{mmHg}$ or $\geq 12 \mathrm{mmHg}$ was 0.99 and 0.92 , respectively, with liver stiffness cutoff values of $13.6 \mathrm{kPa}$ (sensitivity: 97\%) and 17.6 kPa (sensitivity: $94 \%$ ) in patients with hepatitis C. ${ }^{18}$ In addition, liver stiffness measured by TE was correlated with the presence of esophageal varices in patients with hepatitis C virus (HCV)-related cirrhosis. $^{17,19}$ Therefore, US elastography can be helpful to stratify the risk for the development of varices and can be indicative of decompensated cirrhosis in cirrhotic patients.

\section{DIAGNOSTIC PERFORMANCE AND CUT-OFF VALUES OF US ELASTOGRAPHY}

\section{TE}

TE is the most extensively validated method among the US elastography techniques as it is a prototype of US elastography. Numerous studies and meta-analyses have demonstrated that liver stiffness values are strongly correlated with the histologic stage of fibrosis in patients with chronic hepatitis B virus (HBV). ${ }^{20-26} \mathrm{Ac}-$ cording to a recent meta-analysis of the performance TE in patients with chronic hepatitis B, the estimated cutoff for F2 (significant fibrosis) was $7.0 \mathrm{kPa}$ (sensitivity, 78\%; specificity, 80\%), F3 was $8.8 \mathrm{kPa}$ (sensitivity, 74.0\%; specificity, 63.8\%), and F4 was $11.7 \mathrm{kPa}$ (sensitivity, 84.6\%; specificity, 81.5\%) ${ }^{27}$ (Table 3). The diagnostic performance of TE is similar in patients with chronic $\mathrm{HBV}$ and $\mathrm{HCV}^{28}$ although cut-off values were different according to the underlying causes of liver cirrhosis. Based on measurements in healthy volunteers from the general population, the mean liver stiffness value has been estimated to be $5.5 \pm 1.6 \mathrm{kPa}{ }^{29}$ The reproducibility of TE was excellent for both intraobserver and interobserver agreement with intraclass correlation coefficients (ICC) generally above 0.9.30,31

\section{Point shear wave speed measurement}

Among the US elastography techniques using point shear wave speed measurement, Virtual Touch Quantification (Siemens Healthcare) has been well validated. In a recent meta-analysis comprised of eight studies including 518 patients, the mean diagnostic accuracy of Virtual Touch Quantification expressed as AUROC was $0.87(95 \% \mathrm{Cl}, 0.83-0.92)$ for the diagnosis of signifiant fibrosis ( $\mathrm{F} \geq 2), 0.91(95 \% \mathrm{Cl}, 0.86-0.96)$ for the diagnosis of severe fibrosis $(\mathrm{F} \geq 3)$, and $0.93(95 \% \mathrm{Cl}, 0.89-0.97)$ for the diagno-

Table 3. Summary of meta-analyses: pooled diagnostic performance of US elastography for significant fibrosis and cirrhosis

\begin{tabular}{|c|c|c|c|c|c|c|c|c|c|c|}
\hline \multirow{2}{*}{ Implementation } & \multirow{2}{*}{$\begin{array}{l}\text { Number of } \\
\text { studies }\end{array}$} & \multirow{2}{*}{ Cause } & \multicolumn{4}{|c|}{ Fibrosis stage $\geq \mathbf{b} 2$} & \multicolumn{4}{|c|}{ Fibrosis stage $=4$} \\
\hline & & & Cut-off & AUC & Sensitivity & Specificity & Cut-off & AUC & Sensitivity & Specificity \\
\hline $\mathrm{TE}^{75}$ & 50 & Variable & $7.65 \mathrm{kPa}$ & 0.84 & - & - & $13.01 \mathrm{kPa}$ & 0.94 & - & - \\
\hline $\mathrm{TE}^{27}$ & 18 & $\mathrm{CHB}$ & $7.0 \mathrm{kPa}$ & - & 78 & 80 & $11.7 \mathrm{kPa}$ & - & 84.6 & 81.5 \\
\hline $\mathrm{TE}^{76}$ & 14 & $\mathrm{CHC}$ & $7.6 \mathrm{kPa}$ & - & 78 & 80 & $15.3 \mathrm{kPa}$ & - & 83 & 90 \\
\hline $\mathrm{TE}^{76}$ & 6 & $\mathrm{CHB}$ & $7.0 \mathrm{kPa}$ & - & 84 & 78 & $11.3 \mathrm{kPa}$ & - & 80 & 89 \\
\hline PSWSM $^{32}$ & 8 & Variable & $1.34 \mathrm{~m} / \mathrm{s}$ & 0.87 & 79 & 85 & $1.80 \mathrm{~m} / \mathrm{s}$ & 0.91 & 92 & 86 \\
\hline PSWSM $^{77}$ & 13 & Variable & $1.30 \mathrm{~m} / \mathrm{s}$ & 0.85 & 74 & 83 & $1.80 \mathrm{~m} / \mathrm{s}$ & 0.93 & 87 & 87 \\
\hline
\end{tabular}

TE, transient elastography; PSWSM, point shear wave speed measurement; $C H B$, chronic hepatitis $B ; C H C$, chronic hepatitis $C$. 
sis of cirrhosis. ${ }^{32}$ The mean value of shear wave velocity using Virtual Touch Quantification in normal liver was lower than $1.3 \mathrm{~m} /$ $\sec ^{33-35}$ Virtual Touch Quantification reproducibility was excellent in both intraobserver and interobserver agreement with the ICC generally above 0.8 (0.84-0.87). ${ }^{33,36,37}$ According to these results, Virtual Touch Quantification has been demonstrated to be a successful diagnostic tool for staging hepatic fibrosis.

Compared to the results from Virtual Touch Quantification (Siemens Healthcare), those from the other point shear wave speed measurement techniques are limited, as they have been recently introduced. ${ }^{38,39}$

\section{Shear wave speed imaging}

ShearWave Elastography (Aixplorer supersonic imagine, France) is the most validated method among the shear wave speed imaging techniques. A previously published report demonstrated that the cut-off values of SWE were $7.1 \mathrm{kPa}$ for significant fibrosis ( $\mathrm{F} \geq$ 2), $8.7 \mathrm{kPa}$ for advanced fibrosis ( $\mathrm{F} \geq 3$ ), and $10.4 \mathrm{kPa}$ for cirrhosis $(F=4)$ in chronic hepatitis $C$ patients with the AUROC of 0.92 for $F \geq 2,0.98$ for $F \geq 3$, and 0.98 for $F \geq 4 .^{40}$ The normal liver stiffness value ranged from 2.6-6.2 $\mathrm{kPa}$ assessed using SWE. ${ }^{41}$ The reproducibility of ShearWave Elastography is excellent with an ICC above $0.90 .^{41-43}$

\section{Method of measuring US elastography}

Patients should fast for 4-6 hours before US elastography, as food intake can increase the liver stiffness value. Right lobe measurements using the intercostal approach which is unaffected by the probe compression against the liver parenchyma, are preferred. Elastography measurements are acquired during breathholding in order to minimize liver motion. Breath-hold at the end of expiration is preferable in order to determine the persistent liver position between acquisitions and to avoid overestimation of the liver stiffness. Having a clear sonic window is important in the sense that adequate shear wave generated by an ARFI push pulse is required for accurate measurement. The measurement depth can be a confounding factor for assessing liver stiffness. ${ }^{44}$ According to the Society of Radiologists in Ultrasound, the ARFI pulse has a sweet spot at a 4-5 cm depth with most US equipment. ${ }^{6}$

For $T E$, successful measurements are validated using the following criteria: the number of valid shots $\geq 10$; the ratio of valid shots to the total number of shots $\geq 60 \%$; and an interquartile range (IQR, reflecting the variability of measurements) less than $30 \%$ of the median liver stiffness measurement (LSM) value (IQR/LSM $\leq$ $30 \%)$. However, for the other US elastography techniques, the minimum number of measurements and the reliability criteria have not yet been well defined. According to the WFUMB recommendations, ${ }^{4,5}$ a median value of 5-10 measurements can be considered as a representative value in point shear wave speed measurement and the mean value of four measurements in shear wave speed imaging.

\section{CONFOUNDING FACTORS AFFECTING THE PERFORMANCE OF US ELASOGRAPHY}

\section{Technical factors}

\section{Different techniques and vendors}

Although liver stiffness measured by US elastography may appear as a unique and fixed physical property of the liver, in fact, the liver stiffness values measured by US elastography are a function of the frequency of shear waves. ${ }^{45,46}$ As different US elastography techniques and vendors use different shear wave frequencies, the liver stiffness values from different vendors are consequently not exchangeable.

\section{Measurement location}

Liver stiffness is recommended to be measured in the right lobe of the liver as it is not altered by the effect of the probe compression against the liver. Liver stiffness measured in the left lobe is higher than that in the right lobe. ${ }^{35,37,47-49}$ The region of interest (ROIs) should be placed in a homogenous area without vessels and artifacts. This principle should be applied to the path of push pulses as well as to ROls, as the area between the push pulse and the ROI should be homogenous in order to obtain the good shear wave propagation.

The depth of measurement can be a confounding factor for assessing liver stiffness. A previously published study reported that liver stiffness had a decreasing tendency according to the increased depth of measurement in the same phantom. ${ }^{44}$ Significant differences were found in all of the different types of US elastography according to the depth of measurement in each vendor's machine and each transducer in the same phantom. ${ }^{44}$ Interaction between liver stiffness and the fibrosis stage is more accurate for measurements at $1-3 \mathrm{~cm}$ below the liver capsule than for superficial measurements between 0 and $1 \mathrm{~cm}$ below the liver capsule. ${ }^{50}$ There can also be artifacts at the area just beneath the liver cap- 
sule. Therefore, the depth of measurement should be $2-5 \mathrm{~cm}$ below the liver capsule. According to the Society of Radiologists in Ultrasound, the ARFI pulse has a sweet spot at 4-5 cm depth with most equipment. ${ }^{6}$

\section{Patient factors}

\section{Inflammatory activity}

US elastography is unreliable for detecting liver fibrosis in patients with acute hepatitis. ${ }^{51-53}$ As inflammatory changes, including edema, can increase the elasticity and viscosity, inflammatory activity has a major impact on liver stiffness. Therefore, acute liver damage can lead to overestimation of the fibrosis stage. Some authors have recommended using different cutoff values of liver stiffness with respect to the alanine aminotransferase (ALT) level. ${ }^{21} \mathrm{~A}$ higher liver stiffness cutoff is required in order to diagnose different degrees of liver fibrosis in patients with elevated ALT levels.

\section{Biliary obstruction}

Obstructive cholestasis secondary to benign and malignant etiologies can reversibly increase liver stiffness, ${ }^{54-58}$ as it causes secondary fibrotic or inflammatory changes.

\section{Liver steatosis}

The influence of steatosis on liver stiffness values measured by US elastography is currently controversial, as conflicting results exist. Some report have suggested that US elastography was less accurate for detecting severe fibrosis in NAFLD patients. ${ }^{59,60} \mathrm{How}$ ever, other studies have reported that liver stiffness was not affected by the presence of hepatic steatosis. ${ }^{61,62}$

\section{Hepatic venous congestion}

Hepatic venous congestion can influence US elastography performance. ${ }^{63,64}$ Deformation of hepatic vessels in sinusoidal diseases or vascular disease can increase the liver stiffness. Sinusoidal obstruction syndrome can reversibly increase liver stiffness measurements. ${ }^{65,66}$ In order to avoid overestimation of the liver stiffness, US elastography should be interpreted with caution in patients with hepatic congestion and congestive heart failure.

\section{Liver infiltration}

We must keep in mind that liver stiffness measurement is not specific to liver fibrosis. Diffuse infiltrative liver disease, such as amyloidosis, can also increase the liver stiffness. ${ }^{67}$

\section{Deep inspiration}

Deep inspiration has been shown to increase stiffness measurements compared with a resting expiratory position. ${ }^{35}$

\section{Food intake}

Food intake was seen to significantly increase the liver stiffness measurements in patients with chronic liver disease as well as in healthy controls, ${ }^{68-71}$ as it was associated with an increase in splanchnic and hepatic blood circulation.

\section{Body habitus of patients}

Owing to the fixed depth of measurement in TE, TE is known to be of limited use in patients with ascites, thick subcutaneous fat, narrow intercostal space, and severe obesity. ${ }^{10,31,72}$ A TE XL probe has been introduced and validated for obese patients, and the use of an XL probe reduces the failure rate in obese patients but results in a high rate of unreliable results (approximately 25\%). Body habitus, i.e. narrow intercostal space and severe obesity, can also affect other US elastography methods. ${ }^{73,74}$

\section{CONCLUSION}

US elastography is useful in the assessment of the severity of hepatic fibrosis, longitudinal monitoring of the treatment response and disease progression, estimation of portal hypertension, and predicting the complications associated with liver cirrhosis. In order to maintain the successful and valuable performance of US elastography demonstrated in previously published studies, understanding its operating principles and technical details is crucial. It is necessary to be cautious when interpreting the parameters of US elastography measured under different conditions as there are many factors affecting the results of US elastography.

\section{Conflicts of Interest}

The authors have no conflicts to disclose.

\section{REFERENCES}

1. Friedman SL, Bansal MB. Reversal of hepatic fibrosis -- fact or fantasy? Hepatology 2006;43(2 Suppl 1):S82-S88.

2. Cosgrove D, Piscaglia F, Bamber J, Bojunga J, Correas JM, Gilja OH, et al. EFSUMB guidelines and recommendations on the clinical use of ultrasound elastography. Part 2: Clinical applications. Ultraschall Med 2013;34:238-253. 
3. Bamber J, Cosgrove D, Dietrich CF, Fromageau J, Bojunga J, Calliada $F$, et al. EFSUMB guidelines and recommendations on the clinical use of ultrasound elastography. Part 1: Basic principles and technology. Ultraschall Med 2013;34:169-184.

4. Shiina T, Nightingale KR, Palmeri ML, Hall TJ, Bamber JC, Barr RG, et al. WFUMB guidelines and recommendations for clinical use of ultrasound elastography: Part 1: basic principles and terminology. Ultrasound Med Biol 2015;41:1126-1147.

5. Ferraioli G, Filice C, Castera L, Choi BI, Sporea I, Wilson SR, et al. WFUMB guidelines and recommendations for clinical use of ultrasound elastography: Part 3: liver. Ultrasound Med Biol 2015;41:11611179.

6. Barr RG, Ferraioli G, Palmeri ML, Goodman ZD, Garcia-Tsao G, Rubin J, et al. Elastography Assessment of Liver Fibrosis: Society of Radiologists in Ultrasound Consensus Conference Statement. Radiology 2015;276:845-861.

7. Boursier J, de Ledinghen V, Poynard T, Guéchot J, Carrat F, Leroy V, et al. An extension of STARD statements for reporting diagnostic accuracy studies on liver fibrosis tests: the Liver-FibroSTARD standards. J Hepatol 2015;62:807-815.

8. Ophir J, Céspedes I, Ponnekanti H, Yazdi Y, Li X. Elastography: a quantitative method for imaging the elasticity of biological tissues. Ultrason Imaging 1991;13:111-134.

9. Parker KJ, Doyley MM, Rubens DJ. Imaging the elastic properties of tissue: the 20 year perspective. Phys Med Biol 2011;56:R1-R29.

10. Sandrin L, Fourquet B, Hasquenoph JM, Yon S, Fournier C, Mal F, et al. Transient elastography: a new noninvasive method for assessment of hepatic fibrosis. Ultrasound Med Biol 2003;29:1705-1713.

11. Yeh WC, Li PC, Jeng YM, Hsu HC, Kuo PL, Li ML, et al. Elastic modulus measurements of human liver and correlation with pathology. Ultrasound Med Biol 2002;28:467-474.

12. Fung J, Lai CL, Wong DK, Seto WK, Hung I, Yuen MF. Significant changes in liver stiffness measurements in patients with chronic hepatitis B: 3-year follow-up study. J Viral Hepat 2011;18:e200e205.

13. Vergniol J, Foucher J, Castéra L, Bernard PH, Tournan R, Terrebonne $E$, et al. Changes of non-invasive markers and FibroScan values during HCV treatment. J Viral Hepat 2009;16:132-140.

14. Martinez SM, Foucher J, Combis JM, Métivier S, Brunetto M, Capron $D$, et al. Longitudinal liver stiffness assessment in patients with chronic hepatitis $C$ undergoing antiviral therapy. PLoS One 2012;7:e47715.

15. Stasi C, Arena U, Zignego AL, Corti G, Monti M, Triboli E, et al. Longitudinal assessment of liver stiffness in patients undergoing antiviral treatment for hepatitis C. Dig Liver Dis 2013;45:840-843.

16. Ogawa E, Furusyo N, Murata M, Ohnishi H, Toyoda K, Taniai $H$, et al. Longitudinal assessment of liver stiffness by transient elastography for chronic hepatitis B patients treated with nucleoside analog.
Hepatol Res 2011;41:1178-1188.

17. Colecchia A, Montrone L, Scaioli E, Bacchi-Reggiani ML, Colli A, Casazza $G$, et al. Measurement of spleen stiffness to evaluate portal hypertension and the presence of esophageal varices in patients with HCV-related cirrhosis. Gastroenterology 2012;143:646-654.

18. Vizzutti F, Arena U, Romanelli RG, Rega L, Foschi M, Colagrande $S$, et al. Liver stiffness measurement predicts severe portal hypertension in patients with HCV-related cirrhosis. Hepatology 2007;45:1290-1297.

19. Sharma $P$, Kirnake V, Tyagi $P$, Bansal N, Singla V, Kumar $A$, et al. Spleen stiffness in patients with cirrhosis in predicting esophageal varices. Am J Gastroenterol 2013;108:1101-1107.

20. Kim SU1, Ahn SH, Park JY, Kang W, Kim DY, Park YN, et al. Liver stiffness measurement in combination with noninvasive markers for the improved diagnosis of B-viral liver cirrhosis. J Clin Gastroenterol 2009;43:267-271.

21. Chan HY, Wong GH, Choi PL, Chan AH, Chim AL, Yiu KL, et al. Alanine aminotransferase-based algorithms of liver stiffness measurement by transient elastography (Fibroscan) for liver fibrosis in chronic hepatitis B. J Viral Hepat 2009;16:36-44.

22. Marcellin P, Ziol M, Bedossa P, Douvin C, Poupon R, de Lédinghen $V$, et al. Non-invasive assessment of liver fibrosis by stiffness measurement in patients with chronic hepatitis B. Liver Int 2009;29:242-247.

23. Wong GL, Wong VW, Choi PC, Chan AW, Chim AM, Yiu KK, et al. Metabolic syndrome increases the risk of liver cirrhosis in chronic hepatitis B. Gut 2009;58:111-117.

24. Wang JH, Changchien CS, Hung CH, Eng HL, Tung WC, Kee KM, et al. FibroScan and ultrasonography in the prediction of hepatic fibrosis in patients with chronic viral hepatitis. J Gastroenterol 2009;44:439-446.

25. Sporea I, Sirli R, Deleanu A, Tudora A, Popescu A, Curescu M, et al. Liver stiffness measurements in patients with HBV vs HCV chronic hepatitis: a comparative study. World I Gastroenterol 2010;16:48324837.

26. Osakabe K, Ichino N, Nishikawa T, Sugiyama H, Kato M, Kitahara $S$, et al. Reduction of liver stiffness by antiviral therapy in chronic hepatitis B. J Gastroenterol 2011;46:1324-1334.

27. Chon YE, Choi EH, Song KJ, Park JY, Kim DY, Han KH, et al. Performance of transient elastography for the staging of liver fibrosis in patients with chronic hepatitis B: a meta-analysis. PLoS One 2012;7:e44930.

28. Cardoso AC, Carvalho-Filho RJ, Stern C, Dipumpo A, Giuily N, Ripault MP, et al. Direct comparison of diagnostic performance of transient elastography in patients with chronic hepatitis $B$ and chronic hepatitis C. Liver Int 2012;32:612-621.

29. Roulot D, Czernichow S, Le Clésiau H, Costes JL, Vergnaud AC, Beaugrand M. Liver stiffness values in apparently healthy subjects: influence of gender and metabolic syndrome. J Hepatol 
2008;48:606-613.

30. Roca B, Resino E, Torres V, Herrero E, Penades M. Interobserver discrepancy in liver fibrosis using transient elastography. J Viral Hepat 2012;19:711-715.

31. Fraquelli M, Rigamonti C, Casazza G, Conte D, Donato MF, Ronchi G, et al. Reproducibility of transient elastography in the evaluation of liver fibrosis in patients with chronic liver disease. Gut 2007;56:968973.

32. Friedrich-Rust M, Nierhoff J, Lupsor M, Sporea I, Fierbinteanu-Braticevici C, Strobel D, et al. Performance of Acoustic Radiation Force Impulse imaging for the staging of liver fibrosis: a pooled metaanalysis. J Viral Hepat 2012;19:e212-e219.

33. Guzmán-Aroca F, Reus M, Berná-Serna JD, Serrano L, Serrano C, Gilabert $A$, et al. Reproducibility of shear wave velocity measurements by acoustic radiation force impulse imaging of the liver: a study in healthy volunteers. J Ultrasound Med 2011;30:975-979.

34. Kim JE, Lee JY, Kim YJ, Yoon JH, Kim SH, Lee JM, et al. Acoustic radiation force impulse elastography for chronic liver disease: comparison with ultrasound-based scores of experienced radiologists, Child-Pugh scores and liver function tests. Ultrasound Med Biol 2010;36:1637-1643.

35. Karlas T, Pfrepper C, Wiegand J, Wittekind C, Neuschulz M, Mössner J, et al. Acoustic radiation force impulse imaging (ARFI) for noninvasive detection of liver fibrosis: examination standards and evaluation of interlobe differences in healthy subjects and chronic liver disease. Scand J Gastroenterol 2011;46:1458-1467.

36. Bota S, Sporea I, Sirli R, Popescu A, Danila M, Costachescu D. Intraand interoperator reproducibility of acoustic radiation force impulse (ARFI) elastography--preliminary results. Ultrasound Med Biol 2012;38:1103-1108

37. D'Onofrio M, Gallotti A, Mucelli RP. Tissue quantification with acoustic radiation force impulse imaging: Measurement repeatability and normal values in the healthy liver. AJR Am J Roentgenol 2010;195:132-136.

38. Ferraioli G, Tinelli C, Lissandrin R, Zicchetti M, Dal Bello B, Filice G, et al. Point shear wave elastography method for assessing liver stiffness. World J Gastroenterol 2014;20:4787-4796.

39. Ling W, Lu Q, Quan J, Ma L, Luo Y. Assessment of impact factors on shear wave based liver stiffness measurement. Eur J Radiol 2013;82:335-341.

40. Ferraioli G, Tinelli C, Dal Bello B, Zicchetti M, Filice G, Filice C, et al. Accuracy of real-time shear wave elastography for assessing liver fibrosis in chronic hepatitis C: a pilot study. Hepatology 2012:56:2125-2133.

41. Suh CH, Kim SY, Kim KW, Lim YS, Lee SJ, Lee MG, et al. Determination of normal hepatic elasticity by using real-time shear-wave elastography. Radiology 2014;271:895-900.

42. Ferraioli G, Tinelli C, Zicchetti M, Above E, Poma G, Di Gregorio M, et al. Reproducibility of real-time shear wave elastography in the evaluation of liver elasticity. Eur J Radiol 2012;81:3102-3106.

43. Yoon JH, Lee JM, Han JK, Choi BI. Shear wave elastography for liver stiffness measurement in clinical sonographic examinations: evaluation of intraobserver reproducibility, technical failure, and unreliable stiffness measurements. J Ultrasound Med 2014;33:437-447.

44. Shin HJ, Kim MJ, Kim HY, Roh YH, Lee MJ. Comparison of shear wave velocities on ultrasound elastography between different machines, transducers, and acquisition depths: a phantom study. Eur Radiol 2016 Jan 26. [Epub ahead of print]

45. Tang A, Cloutier G, Szeverenyi NM, Sirlin CB. Ultrasound Elastography and MR Elastography for Assessing Liver Fibrosis: Part 2, Diagnostic Performance, Confounders, and Future Directions. AJR Am J Roentgenol 2015;205:33-40.

46. Tang A, Cloutier G, Szeverenyi NM, Sirlin CB. Ultrasound Elastography and MR Elastography for Assessing Liver Fibrosis: Part 1, Principles and Techniques. AJR Am J Roentgenol 2015;205:22-32.

47. Sporea I, Sirli RL, Deleanu A, Popescu A, Focsa M, Danila M, et al. Acoustic radiation force impulse elastography as compared to transient elastography and liver biopsy in patients with chronic hepatopathies. Ultraschall Med 2011;32(Suppl 1):S46-S52.

48. Boursier J, Isselin G, Fouchard-Hubert I, Oberti F, Dib N, Lebigot J, et al. Acoustic radiation force impulse: a new ultrasonographic technology for the widespread noninvasive diagnosis of liver fibrosis. Eur J Gastroenterol Hepatol 2010;22:1074-1084.

49. Toshima T, Shirabe K, Takeishi K, Motomura T, Mano Y, Uchiyama H, et al. New method for assessing liver fibrosis based on acoustic radiation force impulse: a special reference to the difference between right and left liver. J Gastroenterol 2011;46:705-711.

50. Horster S, Mandel P, Zachoval R, Clevert DA. Comparing acoustic radiation force impulse imaging to transient elastography to assess liver stiffness in healthy volunteers with and without valsalva manoeuvre. Clin Hemorheol Microcirc 2010;46:159-168.

51. Sagir A, Erhardt A, Schmitt M, Haussinger D. Transient elastography is unreliable for detection of cirrhosis in patients with acute liver damage. Hepatology 2008;47:592-595.

52. Arena U, Vizzutti F, Corti G, Ambu S, Stasi C, Bresci S, et al. Acute viral hepatitis increases liver stiffness values measured by transient elastography. Hepatology 2008;47:380-384.

53. Coco B, Oliveri F, Maina AM, Ciccorossi $P$, Sacco R, Colombatto $P$, et al. Transient elastography: a new surrogate marker of liver fibrosis influenced by major changes of transaminases. J Viral Hepat 2007;14:360-369.

54. Millonig G, Reimann FM, Friedrich S, Fonouni H, Mehrabi A, Buchler MW, et al. Extrahepatic cholestasis increases liver stiffness (FibroScan) irrespective of fibrosis. Hepatology 2008;48:1718-1723.

55. Attia D, Pischke S, Negm AA, Rifai K, Manns MP, Gebel MJ, et al. Changes in liver stiffness using acoustic radiation force impulse 
imaging in patients with obstructive cholestasis and cholangitis. Dig Liver Dis 2014;46:625-631.

56. Song ZZ. Extrahepatic cholestasis and liver stiffness by transient elastography. Hepatology 2009;49:1053.

57. Harata M, Hashimoto S, Kawabe N, Nitta Y, Murao M, Nakano T, et al. Liver stiffness in extrahepatic cholestasis correlates positively with bilirubin and negatively with alanine aminotransferase. Hepatol Res 2011;41:423-429.

58. Trifan A, Sfarti C, Cojocariu C, Dimache M, Cretu M, Hutanasu C, et al. Increased liver stiffness in extrahepatic cholestasis caused by choledocholithiasis. Hepat Mon 2011;11:372-375.

59. Gaia S, Carenzi S, Barilli AL, Bugianesi E, Smedile A, Brunello F, et al. Reliability of transient elastography for the detection of fibrosis in non-alcoholic fatty liver disease and chronic viral hepatitis. J Hepatol 2011;54:64-71.

60. Yoneda M, Suzuki K, Kato S, Fujita K, Nozaki Y, Hosono K, et al. Nonalcoholic fatty liver disease: US-based acoustic radiation force impulse elastography. Radiology 2010;256:640-647.

61. Yoneda $M$, Yoneda $M$, Mawatari $H$, Fujita $K$, Endo $H$, lida $H$, et al. Noninvasive assessment of liver fibrosis by measurement of stiffness in patients with nonalcoholic fatty liver disease (NAFLD). Dig Liver Dis 2008:40:371-378.

62. Wong VW, Vergniol J, Wong GL, Foucher J, Chan HL, Le Bail B, et al. Diagnosis of fibrosis and cirrhosis using liver stiffness measurement in nonalcoholic fatty liver disease. Hepatology 2010;51:454-462.

63. Millonig G, Friedrich S, Adolf S, Fonouni H, Golriz M, Mehrabi A, et al. Liver stiffness is directly influenced by central venous pressure. J Hepatol 2010;52:206-210.

64. Frulio N, Laumonier H, Balabaud C, Trillaud H, Bioulac-Sage P. Hepatic congestion plays a role in liver stiffness. Hepatology 2009:50:1674-1675.

65. Fontanilla T, Hernando CG, Claros JC, Bautista G, Minaya J, Del Carmen Vega $\mathrm{M}$, et al. Acoustic radiation force impulse elastography and contrast-enhanced sonography of sinusoidal obstructive syndrome (Veno-occlusive Disease): preliminary results. J Ultrasound Med 2011:30:1593-1598.

66. Oki E, Kakeji Y, Taketomi A, Yamashita Y, Ohgaki K, Harada N, et al. Transient elastography for the prediction of oxaliplatin-associated liver injury in colon cancer patients: a preliminary analysis. J Gastrointest Cancer 2008;39:82-85.

67. Loustaud-Ratti VR, Cypierre A, Rousseau A, Yagoubi F, Abraham J,
Fauchais $\mathrm{AL}$, et al. Non-invasive detection of hepatic amyloidosis: FibroScan, a new tool. Amyloid 2011;18:19-24.

68. Mederacke I, Wursthorn K, Kirschner J, Rifai K, Manns MP, Wedemeyer $H$, et al. Food intake increases liver stiffness in patients with chronic or resolved hepatitis $C$ virus infection. Liver Int 2009;29:1500-1506.

69. Lemoine M, Shimakawa Y, Njie R, Njai HF, Nayagam S, Khalil M, et al. Food intake increases liver stiffness measurements and hampers reliable values in patients with chronic hepatitis $B$ and healthy controls: the PROLIFICA experience in The Gambia. Aliment Pharmacol Ther 2014;39:188-196.

70. Popescu A, Bota S, Sporea I, Sirli R, Danila M, Racean S, et al. The influence of food intake on liver stiffness values assessed by acoustic radiation force impulse elastography-preliminary results. Ultrasound Med Biol 2013;39:579-584.

71. Gersak MM, Badea R, Lenghel LM, Vasilescu D, Botar-Jid C, Dudea SM. Influence of Food Intake on 2-D Shear Wave Elastography Assessment of Liver Stiffness in Healthy Subjects. Ultrasound Med Biol 2016;42:1295-1302.

72. Foucher J, Chanteloup E, Vergniol J, Castera L, Le Bail B, Adhoute X, et al. Diagnosis of cirrhosis by transient elastography (FibroScan): a prospective study. Gut 2006;55:403-408.

73. Pradhan F, Ladak F, Tracey J, Crotty P, Myers RP. Feasibility and reliability of the FibroScan S2 (pediatric) probe compared with the $M$ probe for liver stiffness measurement in small adults with chronic liver disease. Ann Hepatol 2013;12:100-107.

74. Castéra L, Foucher J, Bernard PH, Carvalho F, Allaix D, Merrouche $W$, et al. Pitfalls of liver stiffness measurement: a 5 -year prospective study of 13,369 examinations. Hepatology 2010;51:828-835.

75. Friedrich-Rust M, Ong MF, Martens S, Sarrazin C, Bojunga J, Zeuzem $S$, et al. Performance of transient elastography for the staging of liver fibrosis: a meta-analysis. Gastroenterology 2008;134:960-974.

76. Tsochatzis EA, Gurusamy KS, Ntaoula S, Cholongitas E, Davidson $B R$, Burroughs AK. Elastography for the diagnosis of severity of fibrosis in chronic liver disease: a meta-analysis of diagnostic accuracy. J Hepatol 2011;54:650-659.

77. Bota S, Herkner H, Sporea I, Salzl P, Sirli R, Neghina AM, et al. Meta-analysis: ARFI elastography versus transient elastography for the evaluation of liver fibrosis. Liver Int 2013;33:1138-1147. 